\title{
Optimized Injection Molding of Unfilled and Glass Filled PA6 Gears
}

\author{
Nik Mizamzul Mehat, ${ }^{1,2}$ Shahrul Kamaruddin, ${ }^{2}$ and Abdul Rahim Othman ${ }^{2}$ \\ ${ }^{1}$ Department of Mould Technology, Kolej Kemahiran Tinggi MARA, Balik Pulau, Genting, 11000 Balik Pulau, Penang, Malaysia \\ ${ }^{2}$ School of Mechanical Engineering, Universiti Sains Malaysia, Engineering Campus, 14300 Nibong Tebal, Penang, Malaysia
}

Correspondence should be addressed to Nik Mizamzul Mehat; nik_miza78@yahoo.com

Received 6 June 2013; Accepted 5 November 2013; Published 10 February 2014

Academic Editors: G. T. S. Ho and T. R. Kurfess

Copyright (C) 2014 Nik Mizamzul Mehat et al. This is an open access article distributed under the Creative Commons Attribution License, which permits unrestricted use, distribution, and reproduction in any medium, provided the original work is properly cited.

\begin{abstract}
Shrinkage behavior is a crucial problem in manufacturing plastic molded gear. This is because it negatively affects the dimensional stability and accuracy of the involute profile, as well as the concentricity, roundness, tooth spacing uniformity, and size of the gear. By integrating the Taguchi robust design, Grey relational analysis, and principal component analysis, we investigated the dimensional stability related to the shrinkage of tooth thickness, addendum circle, and dedendum circle of molded gear via the optimization of processing parameters and glass fiber reinforcement. The results revealed that the optimal combination of the processing parameters of the molded gear to achieve minimum shrinkage is melt temperature of $260^{\circ} \mathrm{C}$, packing pressure of $60 \%$, packing time of $5 \mathrm{~s}$, and cooling time of $30 \mathrm{~s}$. The melt temperature showed the highest comparability sequence among the four key process parameters examined, followed by packing pressure, cooling time, and packing time. Meanwhile, the presence of glass fibers induced higher deviations of tooth thickness, addendum circle, and dedendum circle than those of the unfilled polyamide 6 gears.
\end{abstract}

\section{Introduction}

The evolution of plastic gears in power and motion transmission application is manifested in diverse applications in consumer electronic items, including copiers, printers, scanners, and washing machines. Manufacturers of automotive components, such as windshield wipers and power car seats and windows, have also used plastic gearing to produce lightweight and cost-effective drive-train designs. Compared with metallic gears that suffer from chemical corrosion and lubricationrelated failures, as well as high operation and maintenance costs, plastic gears are lighter, generate less noise, have low friction, and are more economical to produce in large quantities with complex shapes using the injection molding process. In addition, the molded plastic gears do not require lubricant and additional finishing operation before being mounted in the transmission system.

Although plastic gears are popular, they have certain drawbacks. Plastic gears can fail by divergent mechanisms. For example, Senthilvelan and Gnanamoorthy [1] observed different types of failures on the Nylon 66 spur gears, including gear tooth wear, cracking at the tooth surface, tooth root cracking, and severe shape deformation. Mao [2] studied acetal gear failure related to fatigue. Li et al. [3] investigated the wear behavior of dissimilar plastic gears and found that higher contact force during the operation causes the driven gear tip and the driver's root to wear fast. Focusing on the same plastic gear failure mode, Mao et al. $[4,5]$ in their work reported that the wear rate in acetal gear increased dramatically when the load reaches a critical value for a specific geometry and running speed. The gear surface showed a slowly wear by means of a low specific wear rate if the gear is loaded below the critical value.

Numerous studies have been conducted to improve the plastic gear limitations by material reinforcement. For example, in a series of studies by Kurokawa et al. [6-8] the effect of the presence of carbon fibers (CFs) as reinforcement on the performance of the plastic gear has been investigated; their results showed that the wear properties of the composite gear filled with CFs differed significantly depending on the composition of CFs at various load capability levels. In the work of Senthilvelan and Gnanamoorthy [9], by incorporating 20\% short glass and 20\% carbon fiber to the Nylon 6/6 gear, the damping capacity of the composite gear has been decreased, 
thereby influencing the noise and heat generation during service. Hirogaki et al. [10] used cotton fiber plain woven filled phenolics resin laminate as the gear material to study the tooth root stress resulting from bending movement under running conditions; the results revealed that the strength of a tooth with a filled fiber angle of $45^{\circ}$ is at the lowest when the load is applied to the tooth tip. In addition, Mendi et al. [11] found that reinforcing the polypropylene gear tooth with metallic wires, subsequently generating a residual compression stress in the structure of the gear tooth, increases the number of cycles of fatigue failure and enhances fatigue strength.

Despite the quality of these studies, the issue related to the dimensional stability in plastic gear during the early stage of gear manufacturing has not been thoroughly described elsewhere. An investigation of the literature related to plastic gears study showed that so much attention is given on plastic gear reinforcement in order to overcome the limitations of plastic gears usage. The dimensional stability of a plastic gear is indispensable to the perfect functioning of the gear when it is running, which should not be underrated of its impact on the final quality of plastic gears produced. During the injection molding process, the dimensions of the molded plastic gear change as the parts cool due to shrinkage. The irreversible changes in dimensions, especially in the involute profile of the plastic gear, as a result of uncontrolled shrinkage due to complexity and inappropriate process parameters setting negatively influence concentricity, roundness, tooth spacing uniformity, and the size of the gear produced. Consequently, the quality of the end molded gear, noise, and vibration as well as the service life of the gear are affected by damage mechanisms such as tooth fatigue, creep, excessive wear, and plastic deformation. In fact, the optimum properties of the plastic material with the most innovative gear and mold design cannot be attained, making them irrelevant without optimal processing parameters during gear manufacturing.

Thus, the main objective of the current study is to explore the effects of optimized injection molding processing parameters on the dimensional stability related to shrinkage behavior in the involute profile of a molded plastic gear. A systematic study on the optimization of processing parameters is conducted via a hybrid integration of the Taguchi parameter design, statistical Grey relational analysis (GRA), and principal component analysis (PCA) by selecting three quality characteristics, namely, tooth thickness and the addendum and dedendum circles. A side-by-side comparison between the unfilled and glass fiber-filled polyamide 6 (PA6) gears was also carried out with regard to the dimensional stability related to shrinkage in the involute profile after the optimization process.

\section{Experimental Procedure}

2.1. Materials. The unfilled PA6 under the grade name of ZISAMIDE TP4210 (Zig Sheng Industrial Co.) as well as 15\% and $30 \%$ glass fiber-filled PA6 denoted as Vitamide BR13 and Vitamide BY16, respectively (Perrite), were specified in this study for the gear materials. The study used the spur

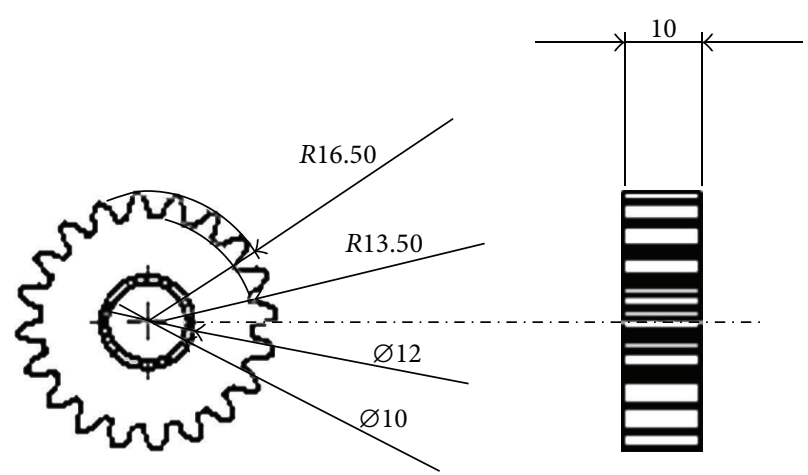

FIGURE 1: Geometry and specifications of spur gear with module $=$ 1.5 ; pressure angle $=20^{\circ}$; number of teeth $=20$; face width $=10 \mathrm{~mm}$.

gear design in compliance with the American Gear Manufacturers Association (AGMA) standards. The geometry and specifications of the gear are shown in Figure 1. The final mold design is prepared after the gear part design has been specified and all requirements affecting the design of the mold including number of cavities, type of mold, types of ejection, and types of venting as well as injection molding machine consideration have been clarified. In this case, the preliminary filling analysis has been previously conducted on the gear model before optimizing the gating system for the gear part. The diaphragm gating system is selected to be incorporated with two plate mold, single gear cavity based on the uniformity of the transient progression of the polymer flow front in the cavity as shown in the analysis.

2.2. Gear Preparation and Fabrication. The PA6 gears were injected using a Battenfeld TM750/210 injection molding machine. The experiment was conducted with four controllable three-level processing parameters, namely, melt temperature, packing pressure, packing time, and cooling time. Other processing parameters, such as mold temperature $\left(60^{\circ} \mathrm{C}\right)$, injection pressure $(60 \mathrm{bar})$, and stroke distance $(60 \mathrm{~mm})$, were kept constant during the experiment. In addition, the Taguchi method based on orthogonal arrays (OA) was used to design the experiments. As discussed by Mehat and Kamaruddin [12], Taguchi's OA are highly fractional orthogonal designs that can be employed to study an entire parameter space with a small number of experiments. Table 1 lists the design of the experiment based on the $\mathrm{L}_{9}\left(3^{4}\right) \mathrm{OA}$ in producing nine trials of unfilled PA6 gears with five repetitions.

2.3. Shrinkage Measurement. All nine trials of the unfilled PA6 gears with five repetitions of each trial were left for 48 hours at room temperature before the measurement of shrinkage (ASTM D955-89). A Rax Vision DC 3000 Mitutoyo profile projector was used to inspect the accuracy of the specific profile of the involute gear teeth following the molding process. The projector was used in measuring the twodimensional (2D) addendum circle, dedendum circle, and tooth thickness using the coordinates of selected points along the gear profile. The gear used in this study was designed 
TABLE 1: Orthogonal array $\mathrm{L}_{9}\left(3^{4}\right)$ of the experimental runs.

\begin{tabular}{lcccc}
\hline Trial no. & & \multicolumn{2}{c}{ Processing parameters/ } & \\
& Melt temperature $\left({ }^{\circ} \mathrm{C}\right)$ & Packing pressure $(\%)$ & Packing time $(\mathrm{s})$ & 5 \\
Cooling time $(\mathrm{s})$ \\
\hline 1 & 260 & 60 & 10 & 30 \\
2 & 260 & 80 & 15 & 40 \\
3 & 260 & 100 & 10 & 50 \\
4 & 280 & 60 & 15 & 50 \\
5 & 280 & 80 & 5 & 40 \\
6 & 280 & 100 & 5 & 40 \\
7 & 300 & 60 & 5 & 50 \\
8 & 300 & 80 & 10 & 30 \\
\hline
\end{tabular}

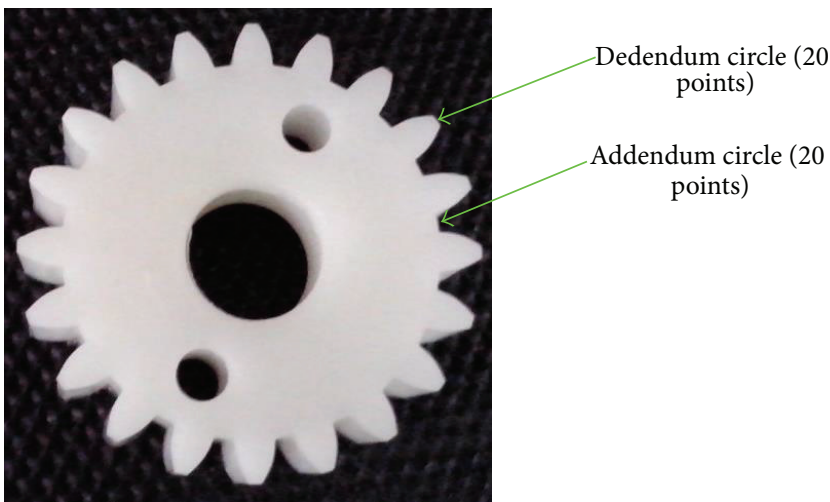

Figure 2: Two-dimensional (2D) addendum and dedendum circles measurement.

with 20 teeth, and therefore in the process of addendum and dedendum circle measurement, 20 edge points of each tooth gear were set in the profile projector (Figure 2). Five injection molded gears from the same batch were measured to determine the repeatability of the part geometry. The relative changes in dimensions due to the shrinkage of the selected quality characteristics were calculated based on the following equation:

$$
S=\frac{D_{m}-D}{D_{m}} \times 100 \% .
$$

In this equation, $S$ represents the relative changes in dimensions due to shrinkage, $D$ is the reading of a corresponding dimension measurement using a profile projector, and $D_{m}$ is the mold cavity dimension.

\section{Implementation of Hybrid Optimization}

After obtaining all the shrinkage data of the molded gears, the sequential steps described below were adopted to determine the optimal combination of the injection molding process parameters based on the proposed Taguchi/GRA/PCA hybrid method.

Step 1: Signal-to-Noise (S/N) Analysis. For constant processing parameters, we calculated the average value of five repeated results for relative changes in dimensions due to shrinkage in tooth thickness, as well as in the addendum and dedendum circles for the final result. Subsequently, the results of relative changes in dimensions in tooth thickness, addendum circle, and dedendum circle were transformed into the $S / N$ ratio. The $S / N$ ratio is a measure of performance of the development of products or processes that are insensitive to noise factors in a controlled manner. The noise factors refer to uncontrollable factors, such as humidity and weather, whose influence on the product or process is unknown and inevitable. Depending on the objective, three different methods of calculating the $S / N$ ratio in the Taguchi method are commonly used, namely, smaller-the-better, bigger-thebetter, and nominal-the-better quality characteristics. The conversion of the results into the $S / N$ ratio involves a series of calculations of the mean squared deviation (MSD).

For this study, the smaller-the-better category was used to characterize the relative changes in the dimensions of tooth thickness, addendum circle, and dedendum circle given as follows:

$$
\frac{S}{N}=-10 \log \left(\frac{1}{N} \sum_{i=1}^{n} y_{i j}^{2}\right),
$$

where $y_{i j}$ is the value of the quality characteristics for the $i$ th trials and $N$ is the number of repetitions. The final measured results and the $S / N$ ratios for the three quality characteristics (i.e., tooth thickness, addendum circle, and dedendum circle) are shown in Table 2.

Step 2: Grey Generation of Raw Data. The $S / N$ ratios were normalized by adopting the GRA, a method to measure the correlation degree between factors based on their similarities or differences. GRA is characterized by less data and multifactor analysis. For the current study, the normalization of the $S / N$ ratios involved the transfer of the original sequence to a comparable sequence. Thus, the smaller-thebetter characteristics of the data sequence were selected to investigate the shrinkage behavior in molded gear and were calculated as follows:

$$
x_{i}^{*}(k)=\frac{\max x_{i}^{(\mathrm{O})}(k)-x_{i}^{(\mathrm{O})}(k)}{\max x_{i}^{(O)}(k)-\min x_{i}^{(O)}(k)} .
$$


TABLE 2: Average changes in dimension and $S / N$ ratios for each trial.

\begin{tabular}{|c|c|c|c|c|c|c|}
\hline \multirow[b]{2}{*}{ Trials } & \multicolumn{3}{|c|}{ Average changes in dimension } & \multicolumn{3}{|c|}{$S / N$ ratio } \\
\hline & Tooth thickness (mm) & Addendum circle (mm) & Dedendum circle (mm) & $\begin{array}{l}\text { Tooth } \\
\text { thickness } \\
(\mathrm{dB})\end{array}$ & $\begin{array}{l}\text { Addendum } \\
\text { circle }(\mathrm{dB})\end{array}$ & $\begin{array}{l}\text { Dedendum } \\
\text { circle }(\mathrm{dB})\end{array}$ \\
\hline 1 & 0.0928 & 0.0225 & 0.0195 & 20.4439 & 32.9303 & 34.1914 \\
\hline 2 & 0.0947 & 0.0173 & 0.0150 & 20.3710 & 35.1167 & 36.1893 \\
\hline 3 & 0.0615 & 0.0159 & 0.0124 & 23.9734 & 35.9816 & 38.1000 \\
\hline 4 & 0.0397 & 0.0156 & 0.0102 & 27.3704 & 36.1456 & 39.8327 \\
\hline 5 & 0.0356 & 0.0167 & 0.0118 & 28.3401 & 35.5302 & 38.5394 \\
\hline 6 & 0.0318 & 0.0144 & 0.0102 & 26.9833 & 36.8383 & 39.7901 \\
\hline 7 & 0.0811 & 0.0162 & 0.0116 & 21.2971 & 35.7943 & 38.6992 \\
\hline 8 & 0.0652 & 0.0159 & 0.0121 & 23.5700 & 35.9580 & 38.3414 \\
\hline 9 & 0.0688 & 0.0153 & 0.0123 & 22.9145 & 36.2715 & 38.1526 \\
\hline
\end{tabular}

TABLE 3: The sequences after data preprocessing (Grey generation).

\begin{tabular}{lccc}
\hline Trials & Tooth thickness & Addendum circle & Dedendum circle \\
\hline Reference sequence & 1.0000 & 1.0000 & 1.0000 \\
Comparability sequence & & & 1.0000 \\
1 & 0.9909 & 1.0000 & 0.6458 \\
2 & 1.0000 & 0.4405 & 0.3072 \\
3 & 0.5480 & 0.2192 & 0.0000 \\
4 & 0.1217 & 0.1773 & 0.2293 \\
5 & 0.0000 & 0.3347 & 0.0076 \\
6 & 0.1703 & 0.0000 & 0.2009 \\
7 & 0.8838 & 0.2672 & 0.2644 \\
8 & 0.5986 & 0.2253 & 0.2978 \\
9 & 0.6808 & 0.1450 & 0 \\
\hline
\end{tabular}

The values of the tooth thickness, addendum circle, and dedendum circle were set as the reference sequence $x_{0}^{(O)}(k)$, $k=1-3$, and the comparability sequences $x_{i}^{(O)}(k), i=1,2$, $3, \ldots, 9, k=1-3$. Table 3 reports the sequences after data preprocessing.

According to Table 3, the deviation sequences $\Delta_{01}(k)$ can be calculated as follows:

$$
\begin{aligned}
& \Delta_{01}(1)=\left|x_{0}^{*}(1)-x_{1}^{*}(1)\right|=|1.0000-0.9909|=0.0091, \\
& \Delta_{01}(2)=\left|x_{0}^{*}(2)-x_{1}^{*}(2)\right|=|1.0000-1.0000|=0.0000, \\
& \Delta_{01}(3)=\left|x_{0}^{*}(3)-x_{1}^{*}(3)\right|=|1.0000-1.0000|=0.0000 .
\end{aligned}
$$

Therefore, $\Delta_{01}=(0.0091,0.0000,0.0000)$.

The same calculation method was performed for $i=1-9$. The results of all $\Delta_{0 i}$ for $i=1-9$ are listed in Table 4 . Based on the data presented in Table $6, \Delta_{\max }(k)$ and $\Delta_{\min }(k)$ can be calculated as follows:

$$
\begin{aligned}
& \Delta_{\max }=\Delta_{02}(1)=\Delta_{01}(2)=\Delta_{01}(3)=1.0000, \\
& \Delta_{\text {min }}=\Delta_{05}(1)=\Delta_{06}(2)=\Delta_{04}(3)=0.0000 .
\end{aligned}
$$

Step 3: Computation of Grey Relational Coefficients of Response Variables. The corresponding Grey relational coefficients (GRC) were calculated using (6). Given that all the process parameters had equal weight, the value of $\zeta$ in this study was defined as 0.5 in the following equation:

$$
\varepsilon_{i}(k)=\frac{\Delta_{\min }+\zeta \Delta_{\max }}{\Delta_{0 i}(k)+\zeta \Delta_{\max }} .
$$

Examples of the GRC $\varepsilon_{1(k)}$ are as follows:

$$
\begin{aligned}
& \varepsilon_{1(1)}=\frac{0.0000+(0.5)(1.0000)}{0.0091+(0.5)(1.0000)}=0.9820, \\
& \varepsilon_{1(2)}=\frac{0.0000+(0.5)(1.0000)}{0.0000+(0.5)(1.0000)}=1.0000, \\
& \varepsilon_{1(3)}=\frac{0.0000+(0.5)(1.0000)}{0.0000+(0.5)(1.0000)}=1.0000 .
\end{aligned}
$$

Thus, $\varepsilon_{1(k)}=(0.9820,1.0000,1.0000), k=1-3$. A similar procedure was applied for $i=1-9$. Table 5 lists the GRC for each trial of the $\mathrm{L}_{9} \mathrm{OA}$.

Step 4: Computation of the Contribution of the Respective Quality Characteristics Using PCA. An engineering judgment or subjective estimation is required to determine the weighted values for each quality characteristic in the process of optimizing a problem related to multiple quality characteristics or 
TABLE 4: Deviation sequences.

\begin{tabular}{lccc}
\hline Deviation sequences & $\Delta_{01}$ & $\Delta_{02}$ & $\Delta_{03}$ \\
\hline Trial 1 & 0.0091 & 0.0000 & 0.0000 \\
Trial 2 & 0.0000 & 0.5595 & 0.3542 \\
Trial 3 & 0.4520 & 0.7808 & 0.6928 \\
Trial 4 & 0.8783 & 0.8227 & 1.0000 \\
Trial 5 & 1.0000 & 0.6653 & 0.7707 \\
Trial 6 & 0.8297 & 1.0000 & 0.9924 \\
Trial 7 & 0.1162 & 0.7328 & 0.7991 \\
Trial 8 & 0.4014 & 0.7747 & 0.7356 \\
Trial 9 & 0.3192 & 0.8550 & 0.7022 \\
\hline
\end{tabular}

TABLE 5: Calculated GRC for nine comparability sequences.

\begin{tabular}{lccc}
\hline Trials & \multicolumn{3}{c}{ Grey relational coefficient $(\mathrm{GRC})$} \\
& $\begin{array}{c}\text { Tooth thickness } \\
(\mathrm{mm})\end{array}$ & $\begin{array}{c}\text { Addendum } \\
\text { circle }(\mathrm{mm})\end{array}$ & $\begin{array}{c}\text { Dedendum } \\
\text { circle }(\mathrm{mm})\end{array}$ \\
\hline 1 & 0.9820 & 1.0000 & 1.0000 \\
2 & 1.0000 & 0.4719 & 0.5854 \\
3 & 0.5252 & 0.3904 & 0.4192 \\
4 & 0.3628 & 0.3780 & 0.3333 \\
5 & 0.3333 & 0.4291 & 0.3935 \\
6 & 0.3760 & 0.3333 & 0.3350 \\
7 & 0.8114 & 0.4056 & 0.3849 \\
8 & 0.5547 & 0.3922 & 0.4046 \\
9 & 0.6104 & 0.3690 & 0.4159 \\
\hline
\end{tabular}

TABLE 6: Eigenvalues and explained variations for principal components.

\begin{tabular}{lcc}
\hline Principal component & Eigenvalue & Explained variation (\%) \\
\hline First & 2.562 & 85.398 \\
Second & 0.424 & 14.139 \\
Third & 0.014 & 0.463 \\
\hline
\end{tabular}

performances. Adopting the conventional method in determining the values for each quality characteristic depends mainly on experience and trial-and-error, which can result in uncertainties during the decision making process. The PCA was utilized in the current study to quantitatively reveal the relative importance of each quality characteristic in the GRA. Specifically, the PCA was adopted to determine the corresponding weighted values for each quality characteristic as described below.

The GRCs of all quality characteristics presented in Table 4 were used to evaluate the correlation coefficient matrix and to determine the corresponding eigenvalues and eigenvectors as in the following equation:

$$
\left(R-\lambda_{k} I_{m}\right) V_{i k}=0 .
$$

In this equation, $\lambda_{k}$ are the eigenvalues; $\sum_{k=1}^{n} \lambda_{k}=n, k=$ $1,2, \ldots, n ; V_{i k}=\left[a_{k 1} a_{k 2} \cdots \cdots a_{k n}\right]^{T}$ are the eigenvectors corresponding to the eigenvalue $\lambda_{k}$. The corresponding eigenvalues and eigenvectors are listed in Tables 6 and 7.

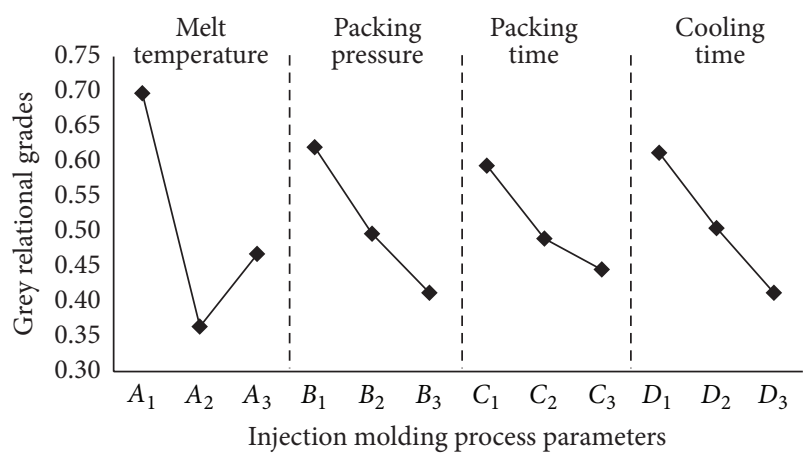

FIGURE 3: Effect of injection molding parameter levels on the dimensional stability related to shrinkage behavior in plastic gear.

The squares of the respective eigenvectors were then selected as the weighted values of the related quality characteristics. The contributions of shrinkage behavior to tooth thickness, addendum circle, and dedendum circle of the molded PA6 gear are reported in Table 8.

The variance contribution for the first principal component characterizing the three quality characteristics is as high as $85.398 \%$. Therefore, the coefficients of $w_{1}, w_{2}$, and $w_{3}$ in (9) were set as $0.3488,0.3773$, and 0.2739 , respectively.

Step 5: Computation of Grey Relational Grades. After determining the corresponding weighted values, $w_{k}$ for each quality characteristic to reflect its relative importance in the GRA by using PCA, the Grey relational grades (GRG) were calculated as follows:

$$
\gamma_{i}=\sum_{k=1}^{n} w_{k} \cdot \varepsilon_{i}(k),
$$

where $w_{k}$ represents the normalized weighted value of factor $k$. The results are listed in Table 9.

\section{Discussion}

4.1. Optimal Combination of Injection Molding Processing Parameters and Their Levels. To determine the optimal combination of injection molding processing parameters for the case of dimensional stability related to shrinkage behavior in tooth thickness, addendum circle, and dedendum circle of the molded gear, the average GRG for each parameter level was calculated by employing the main effects analysis of the Taguchi method. The calculation was done by classifying the GRG corresponding to the levels of the parameters in each column of the orthogonal array and taking the average of those with the same level. The main effects analysis was constructed as shown in Table 10. The results were plotted in Figure 3.

Given that the GRG represents the level of correlation between the reference and the comparability sequences, the larger GRG indicates a stronger correlation between those sequences. Basically, a higher GRG indicates better multiple quality characteristics. Figure 3 shows that the relative changes in dimensions resulting from shrinkage behavior in 
TABLE 7: Eigenvectors for principal components.

\begin{tabular}{lccc}
\hline Quality characteristic & First principal component & $\begin{array}{c}\text { Eigenvector } \\
\text { Second principal component }\end{array}$ & Third principal component \\
\hline Tooth thickness & 0.591 & -0.487 & -0.643 \\
Addendum circle & 0.614 & -0.245 & 0.750 \\
Dedendum circle & 0.523 & 0.838 & -0.154 \\
\hline
\end{tabular}

TABLE 8: Contribution of each individual quality characteristic to the principal component.

\begin{tabular}{lc}
\hline Quality characteristic & Contribution \\
\hline Tooth thickness & 0.3488 \\
Addendum circle & 0.3773 \\
Dedendum circle & 0.2739 \\
\hline
\end{tabular}

TABLE 9: Grey relational grade after computation.

\begin{tabular}{lc}
\hline Trial & Grey relational grade \\
\hline 1 & 0.9951 \\
2 & 0.6594 \\
3 & 0.4382 \\
4 & 0.3570 \\
5 & 0.3894 \\
6 & 0.3457 \\
7 & 0.5089 \\
8 & 0.4414 \\
9 & 0.4528 \\
\hline
\end{tabular}

the tooth thickness, addendum circle, and dedendum circle of the unfilled PA6 molded gear are influenced significantly by the adjustments of the processing parameters. The increment of melt temperature initially decreased the GRG, but then the value slightly increased at level 3 . On the contrary, the GRG is lower when the packing pressure and packing time increased, resulting in more pronounced shrinkage behavior in tooth thickness, addendum circle, and dedendum circle. On the other hand, the GRG value also decreased as the cooling time increased. The more time applied during the cooling phase, the greater of shrinkage behavior in tooth thickness, addendum circle, and dedendum circle of the gear.

As in this case, the best combination of processing parameters and levels could be obtained easily from the main effect analysis by selecting the level of each parameter with the highest GRG. As shown in Figure $3, \mathrm{~A}_{1}, \mathrm{~B}_{1}, \mathrm{C}_{1}$, and $\mathrm{D}_{1}$ provide the highest GRG for factors $\mathrm{A}, \mathrm{B}, \mathrm{C}$, and $\mathrm{D}$, respectively. Consequently, the optimal parameter setting, which statistically results in minimum shrinkage behavior of the tooth thickness, addendum circle, and dedendum circle of the PA6 molded gear, was predicted to be $A_{1}, B_{1}, C_{1}, D_{1}$, that is, melt temperature of $260^{\circ} \mathrm{C}$, packing pressure of $60 \%$, packing time of $5 \mathrm{~s}$, and cooling time of $30 \mathrm{~s}$.

Once the combination of optimal process parameters was identified, the experimental verification test was carried out on five repetitions of gear samples. The purpose of conducting the verification test is to assess the accuracy and to verify the improvement of relative changes in dimension related to those shrinkage behaviors by adopting the hybrid Taguchi/ GRA/PCA optimization method. Table 11 lists the results of the verification test by means of the optimal process parameters $A_{1}, B_{1}, C_{1}, D_{1}$, for the unfilled PA6 molded gear.

Using the optimal process parameter setting of melt temperature of $260^{\circ} \mathrm{C}, 60 \%$ of packing pressure, packing time of $5 \mathrm{~s}$, and cooling time of $30 \mathrm{~s}$, the final unfilled PA6 molded gear exhibited the average of relative changes in dimension related to shrinkage behavior in tooth thickness, addendum circle, and dedendum circle as $9.28 \%, 2.25 \%$, and $1.95 \%$, respectively. Compared with the cavity dimensions of tooth thickness, addendum circle, and dedendum circle, the unfilled PA6 gear demonstrate the optimum average dimensions of $2.1774,32.9013$, and $27.0038 \mathrm{~mm}$, respectively. The results are generally better than those prior to optimization.

4.2. Significance of Process Parameters. To examine the extent to which injection molding parameters significantly influence the performance of molded gear, analysis of variance (ANOVA) of the Taguchi method was performed on the GRG for nine comparability sequences (Table 9). The computed quantities of degree of freedom (DOF), sum of squares $(S)$, variance $(V)$, and percentage contribution $(P)$ are presented in Table 12.

In this case, the percentage contribution of each processing parameter was directly calculated from $S$ because of the nonvalue in the DOF for the error term. The significance of each processing parameter on the dimensional stability can be determined by the percentage contribution. Roy [13] suggested an alternative by using the $10 \%$ rule, which considers the insignificant parameter when its effect is less than $10 \%$ of the highest parameter influence. From the results of ANOVA in Table 12, the melt temperature appears to be the most decisive processing parameter in reducing the shrinkage behavior in tooth thickness, addendum circle, and dedendum circle of the molded gear, with the highest percentage contribution of $52.07 \%$, outweighing the other process variables. The analysis also demonstrates that packing pressure, packing time, and cooling time are significant because their percentages are over $10 \%$, more than the highest parameter influence (5.21\%). The packing pressure, cooling time, and packing time are recorded as $19.58 \%, 17.95 \%$, and $10.04 \%$, respectively. As a broad rule in the effect of shrinkage, it must be anticipated in the design of the mold and requires expert knowledge. Accurate and specific treatment of this phenomenon is a result of years of experience in building molds for products particularly gears. As indicated above the final size of a molded gear can be influenced by the processing parameters. 
TABle 10: Main effects table for Grey relational grades.

\begin{tabular}{lcccc}
\hline Symbol & Process parameters & Level 1 & Level 2 & Level 3 \\
\hline A & Melt temperature $\left({ }^{\circ} \mathrm{C}\right)$ & 0.6975 & 0.3640 & 0.4677 \\
B & Packing pressure (\%) & 0.6203 & 0.4967 & 0.4122 \\
C & Packing time (s) & 0.5941 & 0.4897 & 0.4455 \\
D & Cooling time (s) & 0.6124 & 0.5047 & 0.4122 \\
\hline
\end{tabular}

TABLE 11: Results of verification test.

\begin{tabular}{lccc}
\hline & Tooth thickness & Addendum circle & Dedendum circle \\
\hline Mold cavity dimension $(\mathrm{mm})$ & 2.4000 & 33.6600 & 27.5400 \\
Average dimension after optimization $(\mathrm{mm})$ & 2.1774 & 32.9013 & 27.0038 \\
Relative changes in dimension $(\%)$ & 9.28 & 2.25 & 1.95 \\
\hline
\end{tabular}

From the above, it becomes obvious that with the same mold by changing molding parameters, parts of different sizes can be produced $[14,15]$. In addition the form of the gear teeth itself altered as a result of shrinkage, irrespective of it shrinking away from the mold. The outcome will be impacted on the injected gear where it will be too thin at the top and too thick at the base. Therefore, the pressure angle will amplified, resulting in the possibility of binding as well as greater wear and eventually reduce the gear performance.

\subsection{Influence of Glass Fiber Reinforcement on the Dimensional} Stability of PA6 Molded Gear. To further understand the effects of glass fiber reinforcement on the dimensional stability related to shrinkage behavior in tooth thickness, addendum circle, and dedendum circle, gears made from $15 \%$ and $30 \%$ glass fiber-filled PA6 were also produced using similar optimal processing parameters obtained in the case of the unfilled PA6. The purpose of using the similar optimal processing parameters is to control the changeability in process setting; therefore, the influence of glass fiber reinforcement on the dimensional stability of the molded gears can be directly investigated. Table 13 shows the variation of dimensional stability related to shrinkage behavior in the tooth thickness, addendum circle, and dedendum circle of glass fiber-filled PA6 produced by melt temperature of $260^{\circ} \mathrm{C}$, packing pressure of $60 \%$, packing time of $5 \mathrm{~s}$, and cooling time of $30 \mathrm{~s}$.

As observed in Table 13, the relative changes in dimension related to shrinkage behavior in tooth thickness, addendum circle, and dedendum circle decrease greatly with the addition of glass fiber as reinforcement. At the optimal process parameter settings of melt temperature, packing pressure, packing time, and cooling time, the relative changes in dimension due to shrinkage behavior for PA6 $+15 \%$ GF result in $5.32 \%$, $0.92 \%$, and $0.78 \%$ for tooth thickness, addendum circle, and dedendum circle, respectively. Compared with those of the unfilled PA6, the addition of $30 \%$ glass fiber as reinforcement significantly decreases the relative changes in dimension due to shrinkage behavior in tooth thickness, addendum circle, and dedendum circle to $4.83 \%, 0.58 \%$, and $0.49 \%$, correspondingly. The deviation in the involute profile, especially in the addendum and dedendum circles, is also more than those of the unfilled gears due to the presence of hard glass fiber in the molded surface of the gear. However, less total profile deviation is observed along the gear tooth thickness due to restricted shrinkage resulting from the alignment of glass fibers. The presence of fibers across the tooth section also has an effect on material homogeneity, thus accelerating the deviation compared to the unfilled PA6 gears. Similar circumstances have been reported by Senthilvelan and Gnanamoorthy [16].

\section{Conclusion}

In relating to plastic gear proper sizing have an effect on the overall performance of the gear injected. A metal gear is commonly evaluated by referring to the load data, however, plastics have different properties than metals and are receptive to changing operating conditions. A plastic gear, therefore, must be designed and produced by taking into consideration the load data, environmental conditions, and material properties. In relation to the work carried out, the mold gear was designed with single cavity, two plate mold, and diaphragm gate system in order to provide the uniformity in flow pattern of polymer inside the cavity of the gear part during the filling process. Several trials runs are carried out by using Moldflow Plastic Insight 6.1 (MPI) software in previous work to forecast and visualize the filling pattern or the transient progression of the polymer flow front within the feed system and mold cavity. By established diaphragm gate system and no changing in cavity size, the main focus of the present study is to investigate the effects of the optimized injection molding processing parameters on the dimensional stability related to shrinkage behavior in the involute profile of a molded plastic gear.

Through a systematic Taguchi parameter design/GRA/ PCA hybrid method in the optimization of process parameters, the variation in the dimensional stability due to shrinkage behavior of the thickness, addendum circle, and dedendum circle in PA6 molded gears has been minimized. In addition, through a series of analyses and optimizations of the selected multiple quality characteristics, we found that the optimal combination of processing parameters for the molded gear to achieve minimum relative changes in 
TABLE 12: ANOVA results for the Grey relational grade for nine comparability sequences.

\begin{tabular}{|c|c|c|c|c|c|}
\hline Column & Processing parameters & DOF & $S$ & $V$ & $P$ \\
\hline A & Melt temperature $\left({ }^{\circ} \mathrm{C}\right)$ & 2 & 0.1748 & 0.0874 & 52.07 \\
\hline B & Packing pressure (\%) & 2 & 0.0657 & 0.0329 & 19.58 \\
\hline $\mathrm{C}$ & Packing time (s) & 2 & 0.0349 & 0.0175 & 10.40 \\
\hline $\mathrm{D}$ & Cooling time (s) & 2 & 0.0603 & 0.0301 & 17.95 \\
\hline All others/error & & 0 & 0.0000 & 0.0000 & 0.00 \\
\hline Total & & 8 & 0.3357 & & 100.00 \\
\hline
\end{tabular}

TABLE 13: The effect of GF addition on the involute profile of PA6 molded gear.

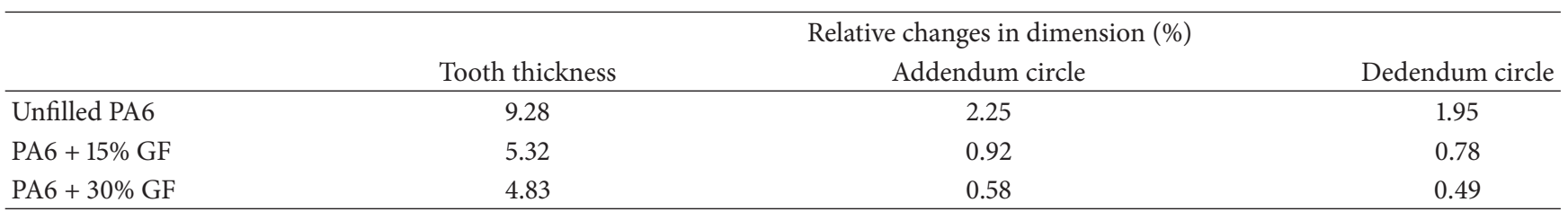

dimension related to shrinkage behavior are $A_{1}, B_{1}, C_{1}$, and $D_{1}$. From the results of ANOVA, the melt temperature appears to be the most decisive processing parameter in reducing the shrinkage behavior of tooth thickness, addendum circle, and dedendum circle of the molded gear with the highest percentage contribution of $52.07 \%$, which outweighs the other process variables. In the case of filled PA6 gears, the presence of glass fibers has induced greater deviation of tooth thickness, addendum circle, and dedendum circle than the nonfilled PA6 gears.

\section{Conflict of Interests}

The authors would like to declare that all financial and material support for the conducting this research and preparation of this paper is clearly termed in the Acknowledgments and there will be no conflict of interests in relation to the financial gain subject to the publication of this paper.

\section{Acknowledgment}

The authors acknowledge the Short-Term Research Grant provided by the University Sains Malaysia, Pulau Pinang, for funding the study that resulted in this paper.

\section{References}

[1] S. Senthilvelan and R. Gnanamoorthy, "Damage mechanisms in injection molded unreinforced, glass and carbon reinforced nylon 66 spur gears," Applied Composite Materials, vol. 11, no. 6, pp. 377-397, 2004.

[2] K. Mao, "A new approach for polymer composite gear design," Wear, vol. 262, no. 3-4, pp. 432-441, 2007.

[3] W. Li, A. Wood, R. Weidig, and K. Mao, "An investigation on the wear behaviour of dissimilar polymer gear engagements," Wear, vol. 271, no. 9-10, pp. 2176-2183, 2011.

[4] K. Mao, W. Li, C. J. Hooke, and D. Walton, "Friction and wear behaviour of acetal and nylon gears," Wear, vol. 267, no. 1-4, pp. 639-645, 2009.
[5] K. Mao, W. Li, C. J. Hooke, and D. Walton, "Polymer gear surface thermal wear and its performance prediction," Tribology International, vol. 43, no. 1-2, pp. 433-439, 2010.

[6] M. Kurokawa, Y. Uchiyama, and S. Nagai, "Performance of plastic gear made of carbon fiber reinforced poly-ether-etherketone," Tribology International, vol. 32, no. 9, pp. 491-497, 1999.

[7] M. Kurokawa, Y. Uchiyama, and S. Nagai, "Performance of plastic gear made of carbon fiber reinforced poly-ether-etherketone: part 2," Tribology International, vol. 33, no. 10, pp. 715$721,2000$.

[8] M. Kurokawa, Y. Uchiyama, T. Iwai, and S. Nagai, "Performance of plastic gear made of carbon fiber reinforced polyamide 12," Wear, vol. 254, no. 5-6, pp. 468-473, 2003.

[9] S. Senthilvelan and R. Gnanamoorthy, "Damping characteristics of unreinforced, glass and carbon fiber reinforced nylon 6/6 spur gears," Polymer Testing, vol. 25, no. 1, pp. 56-62, 2006.

[10] T. Hirogaki, E. Aoyama, T. Katayama, S. Iwasaki, Y. Yagura, and K. Sugimura, "Design systems for gear elements made of cotton fiber-reinforced plastics," Composite Structures, vol. 66, no. 1-4, pp. 47-52, 2004.

[11] F. Mendi, H. Can, and M. K. Külekci, "Fatigue properties of polypropylene involute rack gear reinforced with metallic springs," Materials and Design, vol. 27, no. 5, pp. 427-433, 2006.

[12] N. M. Mehat and S. Kamaruddin, "Optimization of mechanical properties of recycled plastic products via optimal processing parameters using the Taguchi method," Journal of Materials Processing Technology, vol. 211, no. 12, pp. 1989-1994, 2011.

[13] R. K. Roy, Design of Experiment Using the Taguchi Approach: 16 Steps to Product and Process Improvement, John Wiley \& Sons, New York, NY, USA, 2001.

[14] T. C. Chang and E. Faison III, "Shrinkage behavior and optimization of injection molded parts studied by the Taguchi method," Polymer Engineering and Science, vol. 41, no. 5, pp. 703-710, 2001.

[15] S. J. Liao, D. Y. Chang, H. J. Chen et al., "Optimal process conditions of shrinkage and warpage of thin-wall parts," Polymer Engineering and Science, vol. 44, no. 5, pp. 917-928, 2004.

[16] S. Senthilvelan and R. Gnanamoorthy, "Influence of reinforcement on composite gear metrology," Mechanism and Machine Theory, vol. 43, no. 9, pp. 1198-1209, 2008. 

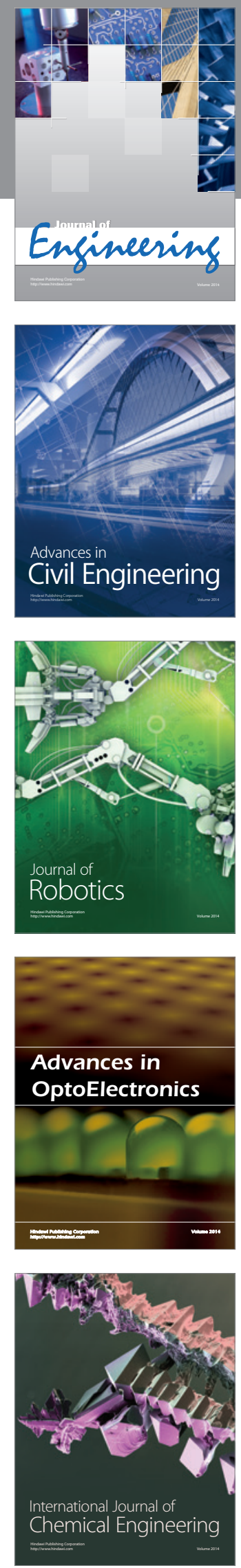

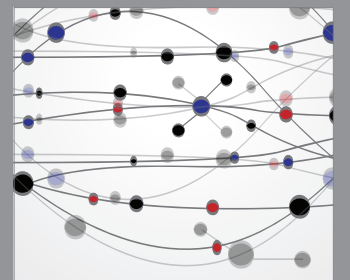

The Scientific World Journal
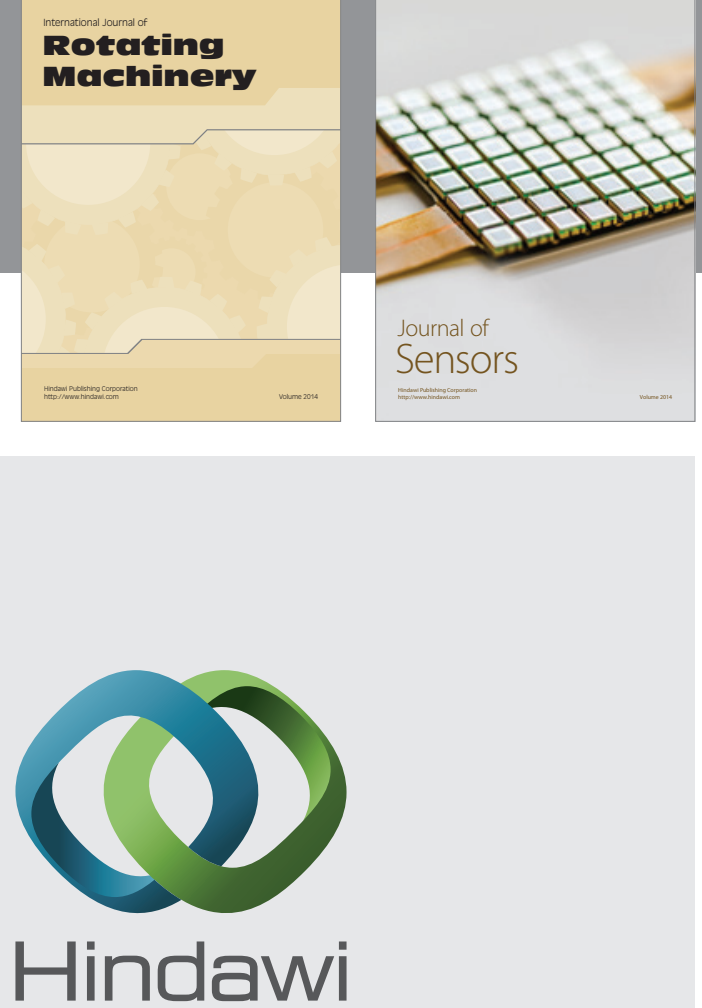

Submit your manuscripts at http://www.hindawi.com

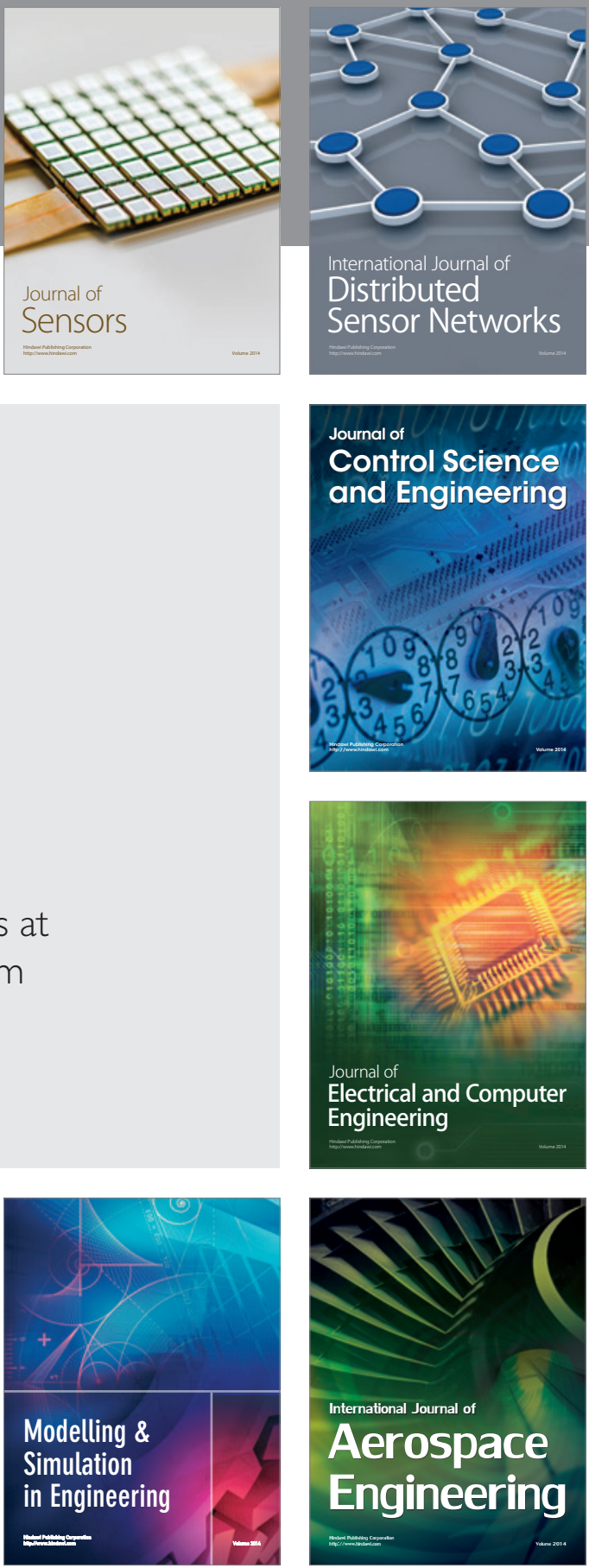

Journal of

Control Science

and Engineering
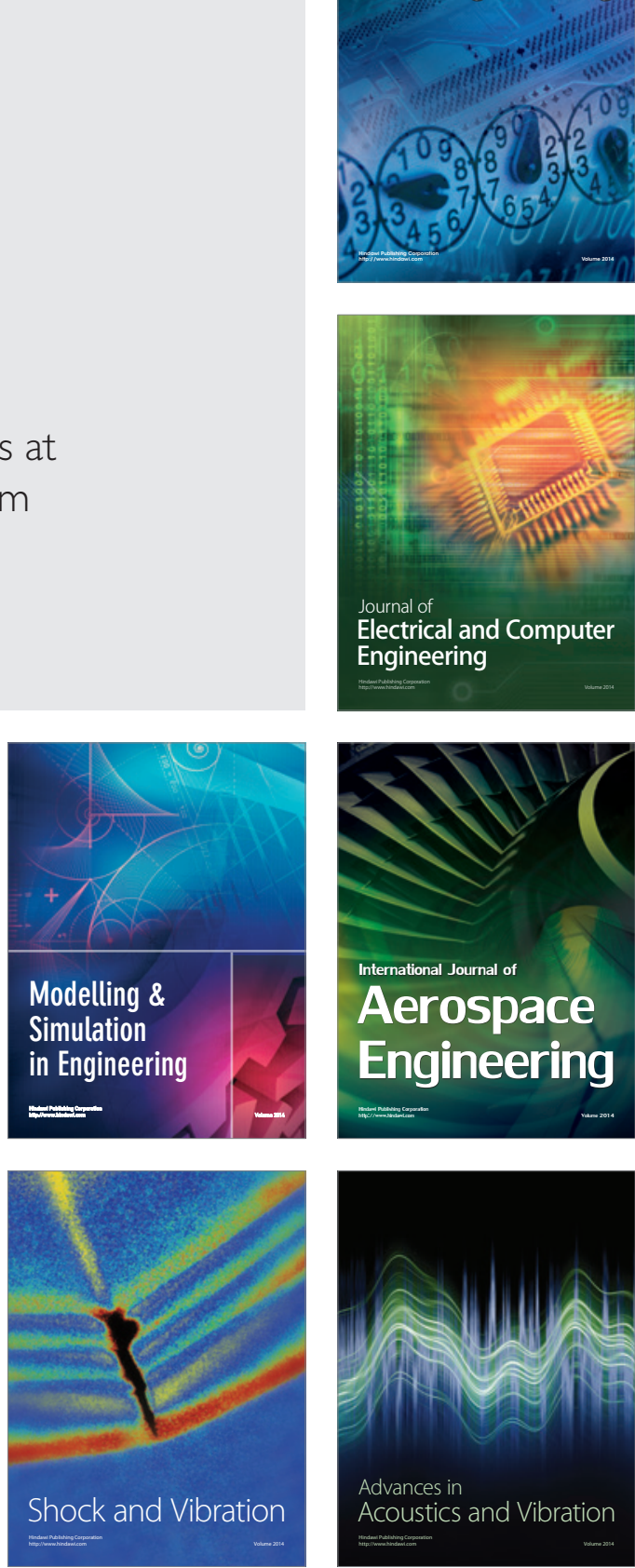